\title{
Modelling and State Variable Feedback Control with Proportional Action of a One-Link Flexible Manipulator Incorporating Payload
}

\author{
M. Khairudin, S. P. Herlambang, Y. Sigit, A. Andik and T. Herawan \\ Deptartment of Electrical Engineering, Universitas Negeri Yogyakarta, Yogyakarta, Jl. Colombo no.1, Karang- \\ malang, Yogyakarta, Indonesia, 55281.
}

\section{Z. Mohamed}

Faculty of Electrical Engineering, Universiti Teknologi Malaysia, UTM, Johor Bahru, 81310 Johor, Malaysia.

\author{
A. Shah and M. N. A. Azman \\ Faculty of Technical and Vocational, Universiti Pendidikan Sultan Idris, 35900 Tanjong Malim, Perak, Malaysia.
}

(Received 27 February 2018; accepted 9 November 2020)

This paper presents a state variable feedback (SVF) control with proportional gain to control a one-link flexible manipulator incorporating payload. The dynamic model of a one-link flexible manipulator is developed through a finite element method. The system is uncertain due to the variation of payloads and numbers of elements. There is a challenge in designing a controller for each number of elements. To obtain the effectiveness of the controllers, a combination of SVF control-based LQR controls with proportional gain is developed for a flexible link manipulator with payload variations. An assessment is conducted to examine the input tracking controller capability of the hub angular position, deflection, hub velocity and end-point residual of the one-link flexible manipulator. The responses of the system are shown in domains of time and frequency, while the SVF control with proportional gain schemes is also discussed. This study finds that the payload effects on the response incorporating payload with SVF control and proportional gain schemes can provide input tracking performance with zero steady state error.

\section{INTRODUCTION}

The study of model and control issues of one-link flexible robot manipulator has been done by previous researchers due to its advantages compared to the rigid ones. In general, a flexible link manipulator consumes less power, requires less material, is more maneuverable and transportable, lighter in weight, requires smaller actuators, and has a greater payload to the ratio of the robot's weight. ${ }^{1}$ Various applications of flexible link manipulator are aimed to maintain space robotics. For instance, nuclear plants are set to utilize industrial robots for simple pick-and-place operations. ${ }^{2}$

Thus, the effort to develop control techniques for a one-link flexible manipulator to obtain and maintain an accurate position is a very challenging one. ${ }^{3}$ By nature, it is a significantly more complex dynamic system. As many problems arise and lead to the need for precise positions and a flexibility system that will generate vibration, the difficulties lie in determining the accurate model. ${ }^{4,5}$

In addition, the issue of complexity emerges when a onelink flexible manipulator hauls the payload. In practice, the robot is produced to perform simple or comprehensive tasks. Previous studies have explained important influences of various payloads on the dynamic behaviour of a one-link flexible manipulator. ${ }^{6}$

The main purpose of the one-link flexible manipulator mod- elling is to obtain accurate models. Several methods to process numerical analysis which can be used include the finite element method (FEM) and the assumed method (AMM). The dynamic characteristics of a one-link flexible manipulator that combines payload, attenuation and inertia hub have been assessed with both methods. ${ }^{7}$ Yong and Hai studied the polynomial expansion and integral technique to develop the fourthorder graded beams. ${ }^{8}$ Using the FEM, Martins et al. performed an investigation to acquire a good system representation. ${ }^{4}$ In addition, Khairudin et al. developed the model through Euler Lagrange and AMM to combine various load profiles. ${ }^{9}$ Specifically, the use of the FEM is to model the flexible link manipulator in the dynamic system and motion modelling as a combination of the elastic deformation and the rigid displacement for each link. ${ }^{10}$

Recently, there has been a great interest in the field of control strategies developments to be used on the current one-link flexible manipulator. The control difficulty of a one-link flexible manipulator is compounded by an obviousness in which the inputs of control, such as unpredictable disturbances, raise a resilient vibration for the structure of the manipulator. On the other hand, the difficulty of the modelling increases drastically compared to the same process in the rigid manipulator case. Dogan and Istefanopulos used the FEM to illustrate the deflection in a flexible manipulator robot, ${ }^{11}$ while Schindele and Aschemann used a Linear Quadratic Regulator (LQR) to 


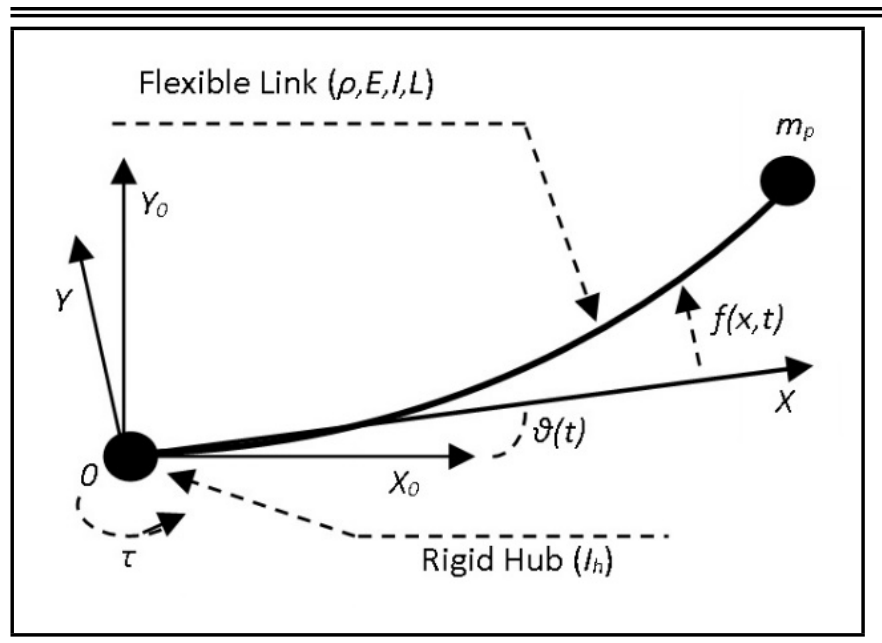

Figure 1. Schematic diagram of flexible link.

control the flexible link with an internal angle transducer for horizontal positioning. ${ }^{12}$ In addition, Khairudin et al. used a LQR developed with LMI to gain a robust control on flexible manipulator with payload variation. ${ }^{13}$ Alandoli et al. reduced vibration on one-link flexible manipulator using a LQR controller by making comparisons with PID control. ${ }^{14}$

Furthermore, on the subject of controlling the position of one-link flexible manipulator, Rana and Deepika developed a LQR which was compared to a state variable feedback (SVF) controller using a pole placement approach for obtaining a better performance. ${ }^{15}$ To optimize the LQR, Razmjooy et al. modified the regulator term weighting of the LQR using the technique of gray wolf optimizer. ${ }^{16}$ On the other hand, Deng et al. proposed a control strategy with an optimal combined input shaper and LQR to ensure the vibration suppression of the flexible manipulator. ${ }^{17}$ Tahir et al. combined the LQR with three command shapers to control position and suppress a residual vibration of a one-link flexible manipulator. ${ }^{18}$ Another design used output-based input shaping incorporated with a LQR to achieve an optimal control of one-link flexible manipulator. ${ }^{19,20}$

In regard to previous studies, there have not been many studies which focus on the techniques to control vibration suppression and input tracking on a one-link flexible manipulator incorporating payload in the tip position area. For this reason, this study presents the technique to control one-link flexible manipulator with various payloads using state variable feedback (SVF). This paper provides a practical design for a SVF control with the proportional action of a one-link flexible manipulator integrating payload. This paper also reveals one-link flexible manipulator modelling with various numbers of elements using the FEM method. The various numbers of elements on the model of a flexible manipulator are challenging because as they increase, the number of the order on the flexible manipulator system will increase as well, and hence a different proportional gain is required. However, most of investigations on the SVF control are limited with one dynamic model system only.

The comparison of system responses with various payloads becomes a challenge as it has not been addressed by previous studies focusing on the SVF control. The system responses are
Table 1. Parameters of the one-link flexible manipulator.

\begin{tabular}{|c|c|c|c|}
\hline Symbol & Parameter & Value & Unit \\
\hline$E$ & Young modulus & $7.11 \times 10^{10}$ & $\mathrm{Nm}^{2}$ \\
$\rho$ & Mass density & 2710 & $\mathrm{kgm}^{-1}$ \\
$M_{l}$ & Mass of link & 0.08 & $\mathrm{~kg}$ \\
$M_{p}$ & Payload mass max & 0.2 & $\mathrm{~kg}$ \\
$I$ & Moment of inertia & $5.25 \times 10^{-11}$ & $\mathrm{~m}^{4}$ \\
$J_{p}$ & Payload inertia max & $0.05 \times 10^{-3}$ & $\mathrm{kgm}^{2}$ \\
$I_{b}$ & Beam inertia & 0.04 & $\mathrm{kgm}^{2}$ \\
$l$ & Length & 0.9 & $\mathrm{~m}$ \\
& Width & $19.01 \times 10^{-3}$ & $\mathrm{~m}$ \\
& Thickness & $3.20 \times 10^{-3}$ & $\mathrm{~m}$ \\
\hline
\end{tabular}

delivered in the domains of time and frequency. The development of a control system with SVF and proportional action for one-link flexible manipulator with various payloads attached to the tip position of link has not been investigated by previous studies. In addition, this study presents the modelling using the FEM with several variations of the numbers of elements. The changing of variations in the number of elements for a onelink flexible manipulator affects the number in the state matrix of one-link flexible manipulator, thereby changing the size of controller gain.

This paper begins with an analysis on one-link flexible manipulator, followed by modelling using FEM, and the technique of a SVF control system development with proportional action. The next section details the results of the input tracking and vibration suppression in the hub angle, deflection, angular velocity and end-point residual. The responses are presented in the domains of time and frequency. The final results show that a SVF control with proportional action can provide input tracking and vibration suppression on various payloads.

\section{THE ONE-LINK FLEXIBLE MANIPULATOR}

Several boundaries in the acquiring process of dynamic equations of one-link flexible manipulator using FEM are briefly discussed in this section. The structure of one link flexible manipulator system can be seen in Fig. 1.

$I, E, A$ were area moments of inertia, Young modulus and cross-sectional area, respectively. Furthermore $\rho$ and $I_{h}$ were mas density and hub inertia, respectively. The one-link flexible manipulator in this study was designed with specifications as shown in Table 1.

In addition, $\theta(t)$ and $y(x, t)$ were the angular displacement and total displacement, respectively. The point on the manipulator with an $x$ distance from the hub is obtained as a function of both elastic deflection $f(x, t)$ and rigid body motion $\theta(t)$ calculated from the line $O X$ as

$$
y(x, t)=f(x, t)+x \theta(t) .
$$

Employing the standard FE method to accomplish dynamic problems directs to the familiar formula

$$
f(x, t)=N_{a}(x) Q_{a}(t)
$$

where $Q_{a}(t)$ and $N_{a}(x)$ presented the nodal displacement and shape function respectively. Approximating to partitioning into $n$ elements for a link of manipulator was the beginning step in the FEM. As an effect of using the EulerBernouli proposition, the FEM prosecuted each node to hold 


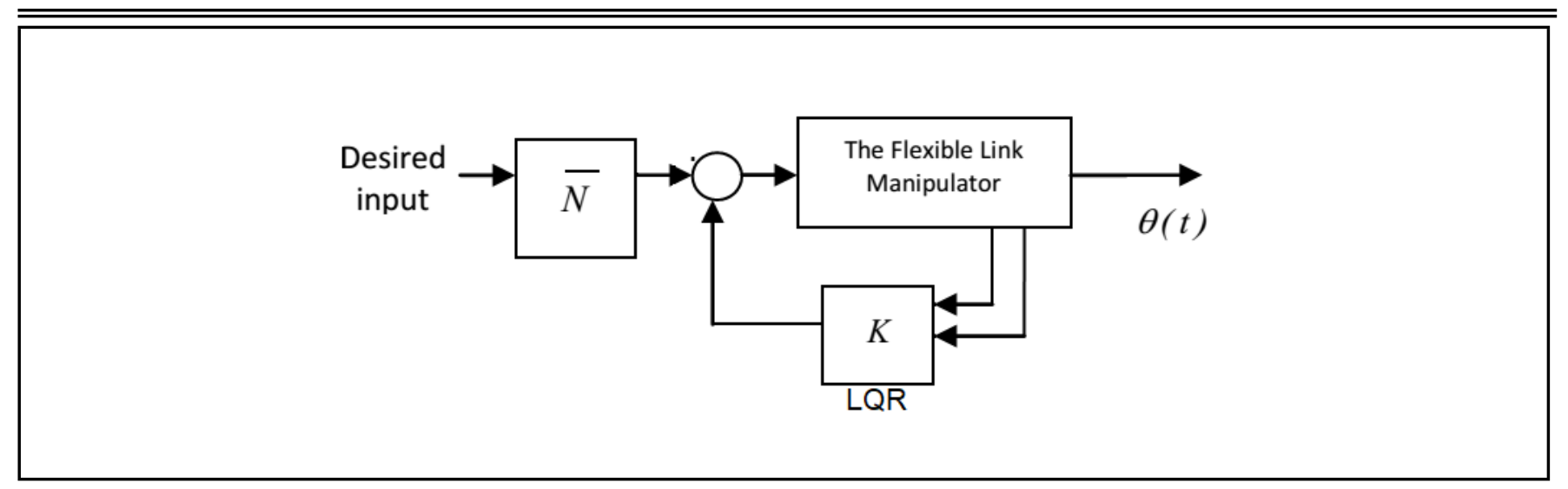

Figure 2. Block diagram of SVF control based LQR.

a transverse deflection and rotation. Furthermore, for a length of element $l$, the shape function was achieved as $N_{a}(x)=\left[\begin{array}{llll}\phi_{1}(x) & \phi_{2}(x) & \phi_{3}(x) & \phi_{4}(x)\end{array}\right]$ and element $n$ for the nodal displacement vector can be expressed as $Q_{a}(t)=$ $\left[f_{n-1}(t) \quad \theta_{n-1}(t) \quad f_{n}(t) \theta_{n}(t)\right]$; where $f_{n}(t) ; f_{n-1}(t)$ and $\theta_{n}(t) ; \theta_{n-1}(t)$ were the elastic deflections of the elements and the corresponding rotations, respectively. The $f(x, t)$ from Equation can be substituted into Eq. (1), it can be described as

$$
y(x, t)=N(x) Q_{b}(t) ;
$$

where $N(x)=\left[\begin{array}{ll}x & N_{a}(x)\end{array}\right]$ and $Q_{b}(t)=\left[\theta(t) Q_{a}(t)\right]^{T}$. The $Q_{b}(t)$ and $N(x)$, referred to the new nodal displacement vector and shape function respectively in Eq. (3) incorporate local and global variables. Between these, $N_{a}(x)$ and $Q_{a}(t)$ were local variables whereas the angle $\theta(t)$ and the distance $x$ were global variables. Defining $l_{i}$ and $k=x-\sum_{i=1}^{n-1} l_{i}$ were the length of the $i$-th element and a local variable of the $n$-th element respectively, while the kinetic energy of an element $n$ was obtained as taken from Martins et al. ${ }^{4}$

$$
E_{K}^{n}=\frac{1}{2} \dot{Q}_{b}^{T}\left[\int_{0}^{l} \rho S\left(N^{T} N\right) d k\right] \dot{Q}_{b} .
$$

Furthermore, the potential energy of the element was expressed as

$$
E_{P}^{n}=\frac{1}{2} Q_{b}^{T}\left[\int_{0}^{l} E I\left(\Phi^{T} \Phi\right) d k\right] Q_{b}
$$

where $\Phi=\frac{d^{2} N}{d k^{2}}$. Defining $K_{n}$ and $M_{n}$ as

$$
\begin{aligned}
& K_{n}=\int_{0}^{l} E I\left(\Phi^{T} \Phi\right) d k=\text { element stiffness matrix; } \\
& M_{n}=\int_{0}^{l} \rho S\left(N^{T} N\right) d k=\text { element mass matrix; }
\end{aligned}
$$

the motion of one-link flexible was obtained with the desired dynamic equations as

$$
M \ddot{Q}(t)+D \dot{Q}(t)+K Q(t)=F(t) .
$$

A state space model to construct the dynamic model of uncontrolled system was achieved as

$$
\begin{aligned}
& \dot{x}=A x+B u \\
& y=C x+D u
\end{aligned}
$$

where $A=\left[\begin{array}{cc}0_{m} & I_{m} \\ -M^{-1} K & -M^{-1} D\end{array}\right], B=\left[\begin{array}{l}0_{m x 1} \\ M^{-1}\end{array}\right]$, $C=\left[\begin{array}{ll}0_{m} & I_{m}\end{array}\right], D=\left[\begin{array}{lll}0_{2 m x 1}\end{array}\right]$, and $u=\left[\begin{array}{llll}\tau & 0 & \ldots & 0\end{array}\right]^{T}$. $0_{m}, I_{m}$, and $0_{m x 1}$ were $m \times m$ null matrix, $m \times m$ identity matrix, and $m \times 1$ null vector, respectively.

\section{STATE VARIABLE CONTROL BASED LQR CONTROL}

LQR is a modern control technique to analyse such as the state-space system. The idea proposed is that proceeding the planner's iteration on pole locations can be applied in a full state-feedback for the elements iterations as a cost function $J$. Minimising $J$ with this technique determines the feedback gain matrix in the interest of reaching several compromises between the magnitude, the use of control technique, and the response speed which will ensure a stable system. It is a relatively simple work to use state-space method with an output system. Through state feedback, the system can be stabilized. Figure 2 reveals a schematic diagram of SVF control based LQR for the position control of a one-link flexible manipulator where the desired input was the desired hub angular position and $\theta(t)$ was the actual hub angular position for one-link flexible manipulator.

For the given system, $\dot{x}=A x+B u$, assign the matrix $K$ of the LQR vector $u(t)=-K x(t)$. Accordingly, in the interest of minimizing the performance index, it was constructed in Eq. (10) as

$$
J=\int_{0}^{\infty} x^{T}(t) Q x(t)+u^{T}(t) R u(t) d t
$$

where $R=R^{T}>0$ and $Q=Q^{T} \geq 0$. The quadratic cost function and the linear dynamic system referred to a linear quadratic term. The matrices $R$ and $Q$ represented the control penalty and the state matrices, respectively. When the $Q$ was given by a small value relative to the $R$, it resulted in highpriced control efforts and the state was not converged to zero immediately.

By substituting $u$ into Eq. (10), the cost function $J$ was obtained as

$$
J=\int_{0}^{\infty} x^{T}(t) Q x(t)+(-K x(t))^{T} R(-K x(t)) d t
$$




\begin{tabular}{l}
\hline \hline Table 2. The variables $Q$ and $K$ for LQR controller. \\
\begin{tabular}{|c|rc|c||}
\hline $\begin{array}{c}\text { Number of } \\
\text { elements } \\
(n)\end{array}$ & $Q$ & $K_{L Q R}$ \\
\hline 1 & $Q=\left[\begin{array}{ll}I_{3 \times 3} & 0_{3 \times 3} \\
0_{3 \times 3} & 0_{3 \times 3}\end{array}\right]$ & $\left.\begin{array}{c}K_{1 \times 6}=[4.47,1.83,-0.68, \\
0.59,0.61,-0.10\end{array}\right]$ \\
& $Q=\left[\begin{array}{ll}I_{5 \times 5} & 0_{5 \times 5} \\
0_{5 \times 5} & 0_{5 \times 5}\end{array}\right]$ & $\begin{array}{c}K_{1 \times 10}=[4.47,10.99,-0.43, \\
-3.50,0.13,0.60,0.73, \\
2\end{array}$ & $-0.00,0.26,-0.02]$ \\
\hline
\end{tabular}
\end{tabular}

$$
J=\int_{0}^{\infty} x^{T}(t)\left(Q+K^{T} R K\right) x(t) d t .
$$

This research investigated the tracking performance on the LQR adjusted to a one-link flexible manipulator through arranging the values of vector $K$ and $\bar{N}$ which represented the feedback control rule and the capability of steady state error (proportional gain), respectively. The one-link flexible manipulator was presented in the form of a state space model in Eq. (9) and calculated matrices of $M, K$, and $D$. The LQR gain can be seen as in Table 2 .

The capability of steady state error (proportional gain, $\bar{N}$ ) for the number of elements, $R$ and $I$ were 4.4703, 1 and 20 respectively.

A state variable feedback control with proportional gain scheme to control vibration suppression and body motion in the system is presented in this paper. The suggested control scheme is shown in Fig. 2. Substantially, the function of the controller is to control the position of one-link flexible manipulator to a specified commanded position.

\section{RESULTS AND DISCUSSION}

The one-link flexible manipulator model has been obtained using FEM and executed within the Matlab environment. The investigation conducted shows the influence of payload on the response of the system with and without payload. A simulation on the algorithm based on several elements of 1 and 2 is used to examine the accuracy of the finite element method simulation algorithm into the behaviour characteristics of the one link flexible manipulator. The performance of the SVF control with the response of one-link flexible manipulator is expressed in the domains of time and frequency. A step input with an amplitude of 1.0 is applied as an input at the hub of the one-link flexible manipulator. The system responses consist of hub angular positions, deflections, hub velocity, and end-point residual. The system responses are also evaluated in the frequency domain. This paper analyses the effects of payload variations on the system behaviour. In this analysis, zero payload and payloads of $0.1 \mathrm{~kg}, 0.2 \mathrm{~kg}$, and $0.3 \mathrm{~kg}$, are examined.

This study is conducted in the Matlab and Simulink environment on Intel Pentium 1.70 GHz and 2.00 GB RAM. The system responses are monitored for a duration of $3 \mathrm{~s}$, and the results are recorded with sampling times of $10 \mathrm{~ms}$. The angular position, deflection, hub velocity and end-point residual responses are evaluated and the corresponding responses in the frequency domain are obtained. Settling time and overshoot percentages of the response are evaluated to assess the time response of the angular position, while the evaluation of resonance frequency of performance responses determines the frequency response. Finally, the results of the system performance with zero load and loads of $0.1,0.2$, and $0.3 \mathrm{~kg}$ are compared to inspect the accuracy of the developed control schemes.

\subsection{The System without Payload}

Figure 3 presents the hub angular response of the system with the SVF control based LQR on one-link flexible manipulator with modelling using the FEM one element and with a proportional gain of $\bar{N}=1$ and a tip end without a payload. The response specification is presented in Table 3 . With a proportional gain of $\bar{N}=1$, this technique can not comply with the expected angular position of $1 \mathrm{rad}$. The output still has a big steady state error. To improve the output, the proposed controller is designed to increase a proportional gain of $\bar{N}$ with Eq. (13)

$$
\bar{N}=\frac{\text { input }}{\text { output }}=\frac{1}{0.2237}=4.4703 \text {. }
$$

In other words, the system with SVF control with proportional gain of $\bar{N}=1$ shows that the output system can not obtain input tracking, and thus, it is necessary to increase the proportional gain of $\bar{N}$. Figure 3 presents a hub angular response of the system with the SVF control-based LQR on one-link flexible manipulator with a proportional gain of $\bar{N}=4.4703$.

The performance of responses specification of the SVF control with an initial proportional gain of 1 involving the overshoot percentages, settling time and steady state error are 6.62 , $0.84 \mathrm{~s}$, and $77.63 \%$ respectively. While the improved proportional gain of 4.4703 shows $6.62,0.85 \mathrm{~s}$, and $0 \%$ respectively. It is concluded that the system using the SVF control with an improved proportional gain exhibits more accurate results compared to the initial gain. Moreover, the results also indicate smoother responses with a very small steady state error. Nevertheless, it must be noted that both numbers of elements have similar effects on the overshoot and settling time.

Figure 4 presents the hub angular, deflection, hub velocity, end-point deflection, and the spectral density of those aspects in the one-link flexible manipulator developed by number of element 1 with an improved proportional gain without a payload. The maximum magnitudes of deflection and end-point residual responses of the one-link flexible manipulator with the SVF control and improved proportional gain are $0.42 \mathrm{~mm}$ and 37.55 , respectively. Furthermore, the hub velocity response is $14.55 \mathrm{rad} / \mathrm{s}$.

The hub angular, deflection, hub velocity, end-point deflection, as well as the spectral density of those aspects in the flexible one-link manipulator developed by number of element 2 using a SVF control with an improved proportional gain without payload are examined, as well. The maximum magnitudes of deflection and end-point residual responses of the one-link flexible manipulator with SVF control and improved proportional gain are $0.40 \mathrm{~mm}$ and 25.99 , respectively, while the hub velocity response is $27.97 \mathrm{rad} / \mathrm{s}$.

The maximum deflection responses, hub velocity and endpoint residuals in one-link flexible manipulator without payload using number of element 1 are $0.42 \mathrm{~mm}, 14.55 \mathrm{rad} / \mathrm{s}$, and $37.55 \mathrm{~mm}$, respectively; while those using number of element 


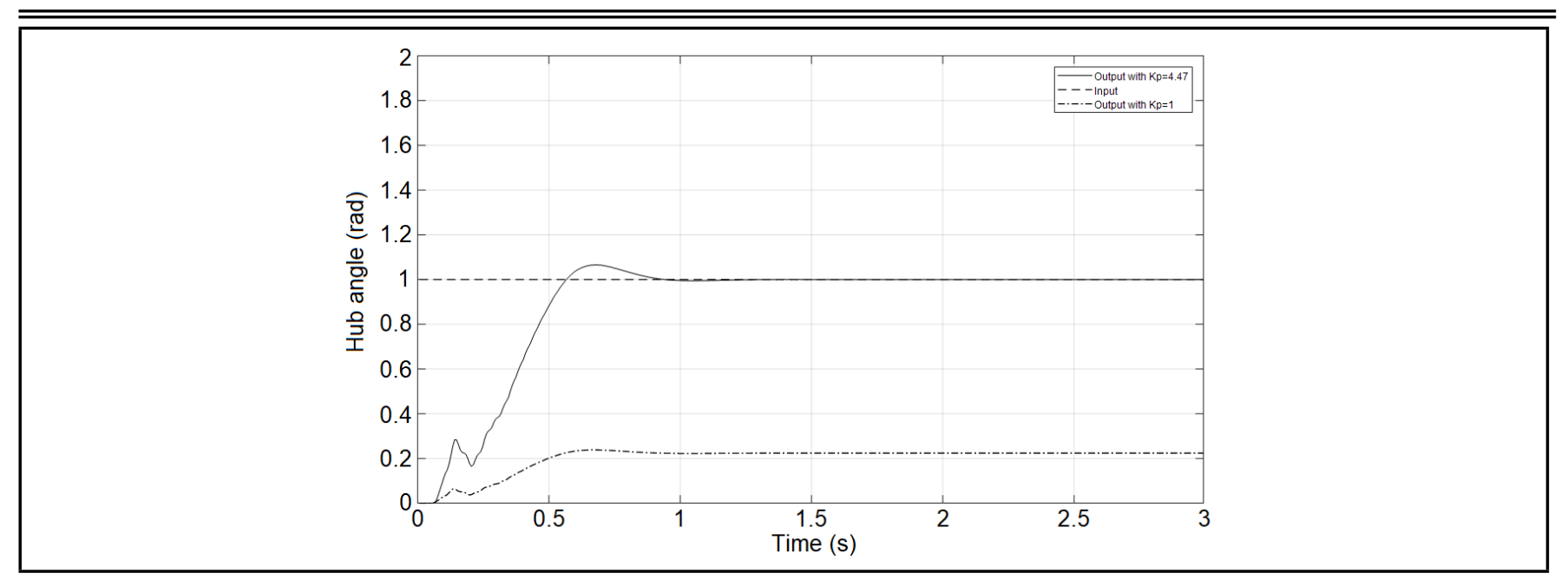

Figure 3. Hub angular with $\bar{N}=1$ and $\bar{N}=4.4703$.

Table 3. Relation between number of element and resonance frequency of flexible manipulator using SVF with improved $\bar{N}$ and without payload.

\begin{tabular}{|c|c|c|c|c|}
\hline $\begin{array}{c}\text { Freq. } \\
\text { domain of }\end{array}$ & $\begin{array}{c}\text { Number of } \\
\text { elements }\end{array}$ & Mode 1 & Mode 2 & Mode 3 \\
\hline Hub angle & 1 & 13.90 & 90.32 & 187.6 \\
& 2 & 5.82 & 34.9 & 75.62 \\
\hline \multirow{2}{*}{ Deflection } & 1 & 20.84 & 90.32 & 187.6 \\
& 2 & 5.82 & 75.62 & 98.89 \\
\hline \multirow{2}{*}{ Hub velocity } & 1 & 20.84 & 90.32 & 187.6 \\
& 2 & 5.82 & 34.9 & 75.62 \\
\hline \multirow{2}{*}{ End point residual } & 1 & 27.79 & 83.38 & 187.6 \\
& 2 & 5.82 & 36.84 & 75.62 \\
\hline
\end{tabular}

2 are $0.40 \mathrm{~mm}, 27.97 \mathrm{rad} / \mathrm{s}$, and $25.99 \mathrm{~mm}$, respectively. It is noted the deflection response on number of element 1 is higher compared to number of element 2. Similarly, the end-point residual also generates a higher response on the number of element 1 compared to the number of element 2. It is found that the increase of the number of elements will accelerate the movement.

Table 3 presents the relationship of the number of elements and the resonance frequency of a flexible manipulator using a SVF control with improved proportional gain $\bar{N}$ without a payload. The frequency responses of the hub angle, deflection, hub velocity and end-point residual with a SVF control and improved proportional gain are obtained. In this study, the second mode of vibration is reflected on the dominant mode characterizing the deflection of dynamic system. The level of hub angle, deflection, hub velocity and end-point residual with a SVF control and improved proportional gain are $90.32 \mathrm{~dB}$, $90.32 \mathrm{~dB}, 90.32 \mathrm{~dB}$, and 83.38, respectively, for number of element 1. Meanwhile for the number of element 2, the level of hub angle, deflection, hub velocity and end-point residual with a SVF control and improved proportional gain are $34.9 \mathrm{~dB}$, $75.62 \mathrm{~dB}, 34.9 \mathrm{~dB}$, and 36.84 , respectively. The increasing number of elements results in more accurate values of the system resonance frequency. Increased mass, damping, stiffness, and state-space matrices are shown to be the main causes. Table 3 presents the relation between the number of elements and resonance frequency of the system inter-related with payload using SVF control and improved proportional gain.

\subsection{The System with Payload}

In order to assess the change on the dynamic characteristics of the system resulted from payloads using SVF, a flexible onelink manipulator which integrates various payloads is investigated. Figure 5 shows the performance of a flexible one-link manipulator developed by a number of elements 1 , involves a hub angular, deflection, hub velocity and end-point residual with a payload of $0.1 \mathrm{~kg}$. The results indicate that a SVF control with improved gain can maintain the input tracking process for various payloads.

The performance of a flexible one-link manipulator developed by a number of elements. One and two use a SVF control with an improved proportional gain reveals the effects of payload inserted at the tip position of the link to the system responses.

Table 4 presents the settling times and overshoot of the angular position response with payloads of $0.1 \mathrm{~kg}, 0.2 \mathrm{~kg}$, and $0.3 \mathrm{~kg}$. It is discovered that by increasing various payloads, the system reveals higher settling times and overshoots.

Accordingly, the results are verified. Despite varied loads, a uniform system performance is accomplished between the one-link flexible manipulator incorporating payload conditions and the system with SVF control and improved proportional gain. It is noted that, by extensive efforts in developing SVF control with improved proportional gain, similar results can be achieved. However, the process is arduous and should be carried out for every condition of various payloads.

Table 4 depicts the performance of the transient responses of a one-link flexible manipulator incorporating payload and various numbers of elements through a SVF control and an improved proportional gain. It is noted that the more payload on the tip position of one-link flexible manipulator, the bigger the settling time and overshoot will be. On the other hand, it is noted that in the system with payload, greater number of constituent elements in the FEM modelling results in smaller or faster settling time and overshoot. In other words, bigger constituent elements allow the one-link flexible manipulator system to be smoother.

Despite varying payloads, a SFV control with proportional gain can reach the expected angular position of $1.00 \mathrm{rad}$. This is in line with the case without payload, as one-link flexible 

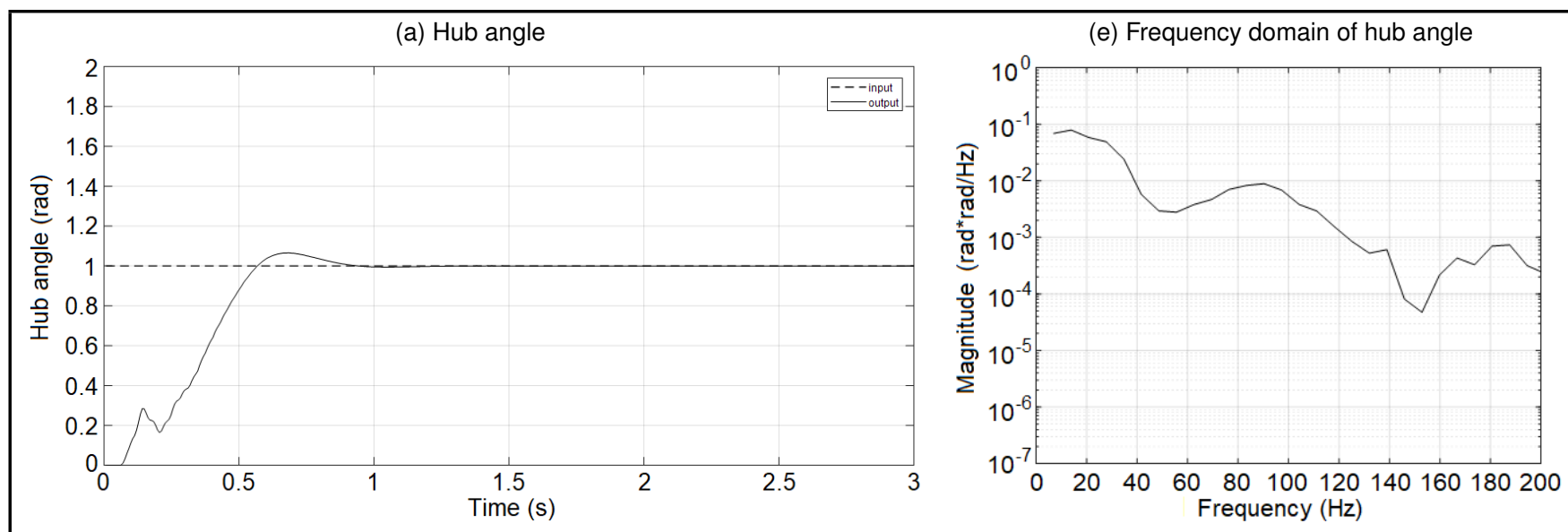

(b) Deflection

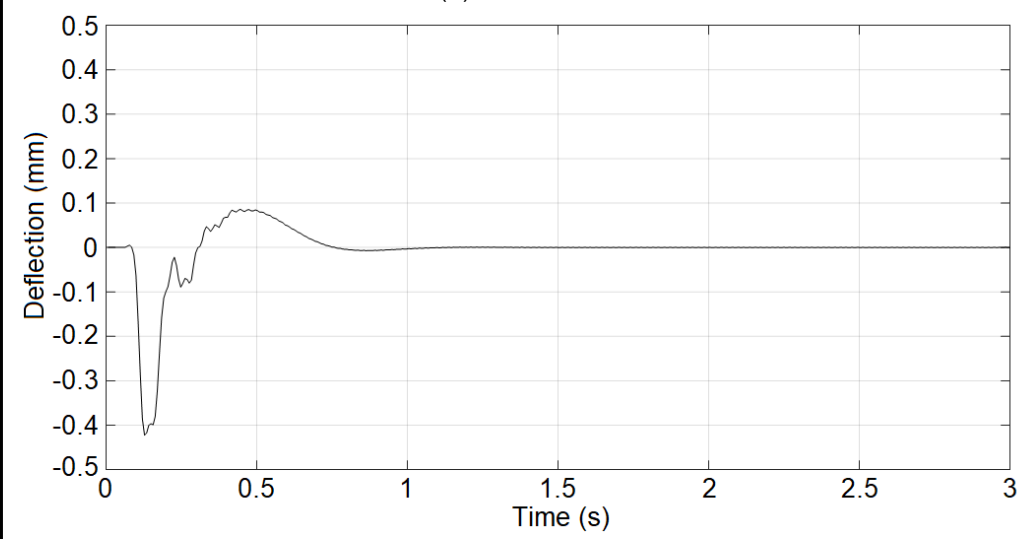

(f) Frequency domain of deflection

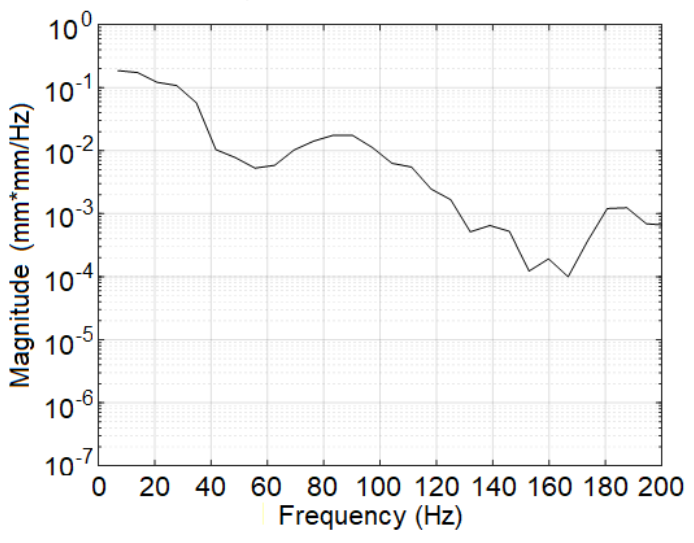

(c) Hub velocity

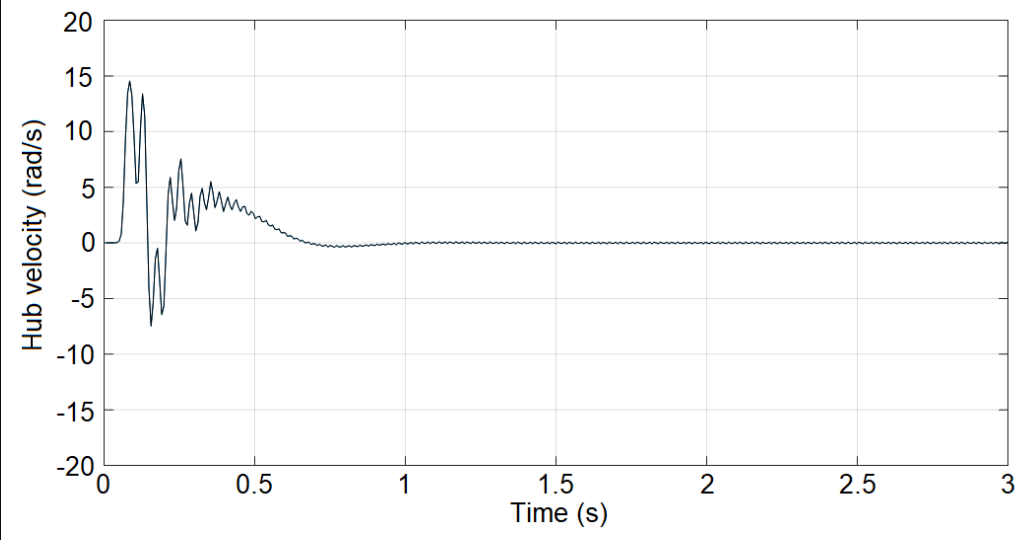

(g) Frequency domain of hub velocity

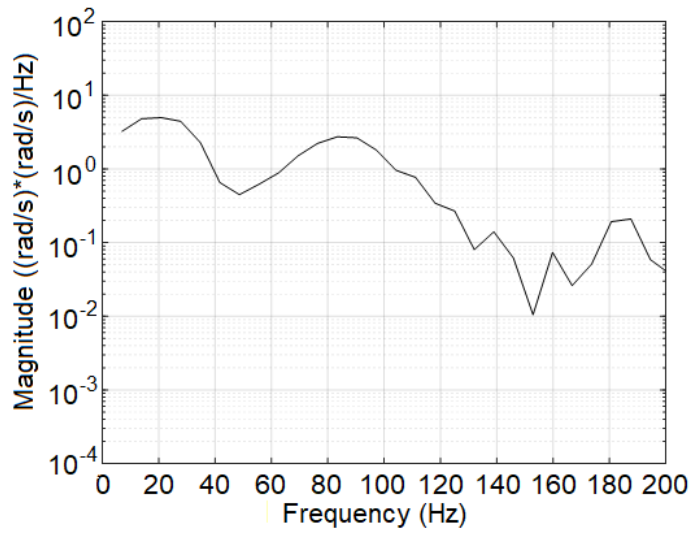

(d) End point residual

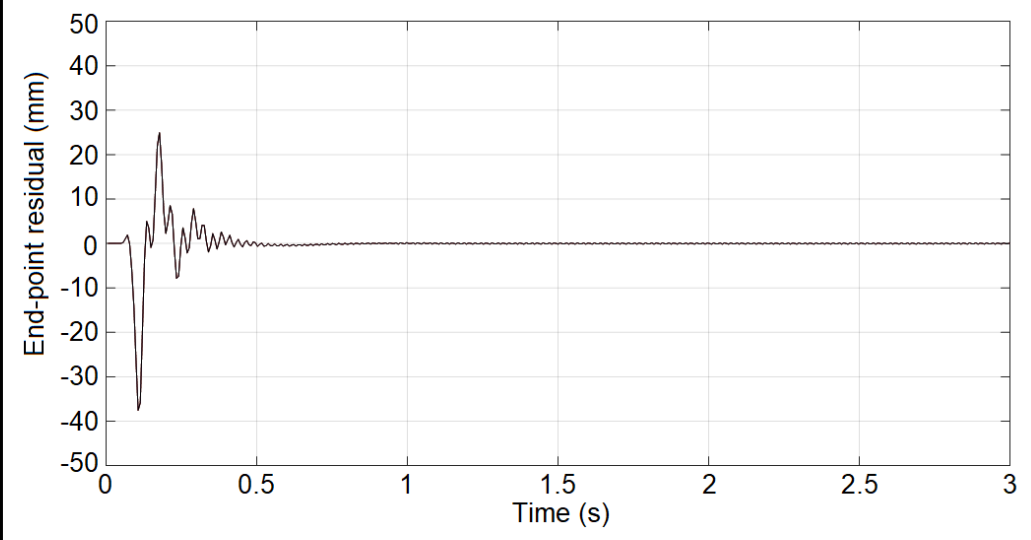

(h) Frequency domain of end point residual

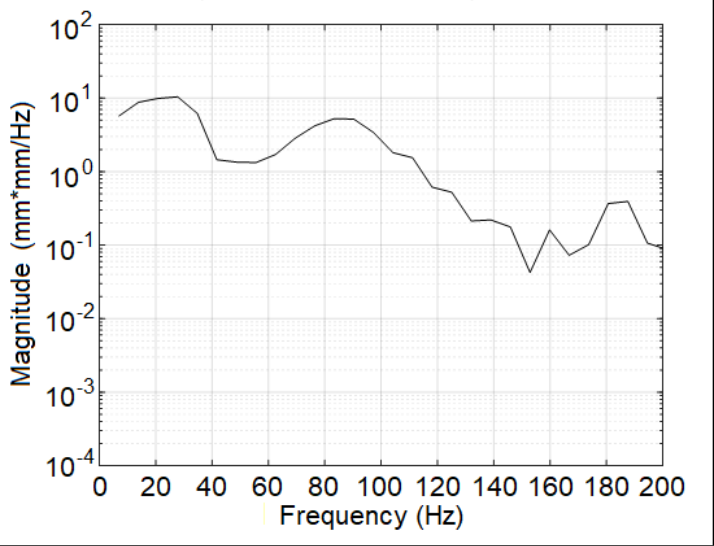

Figure 4. Simulated response of one-link flexible manipulator without payload; Number of elements $=1$. 

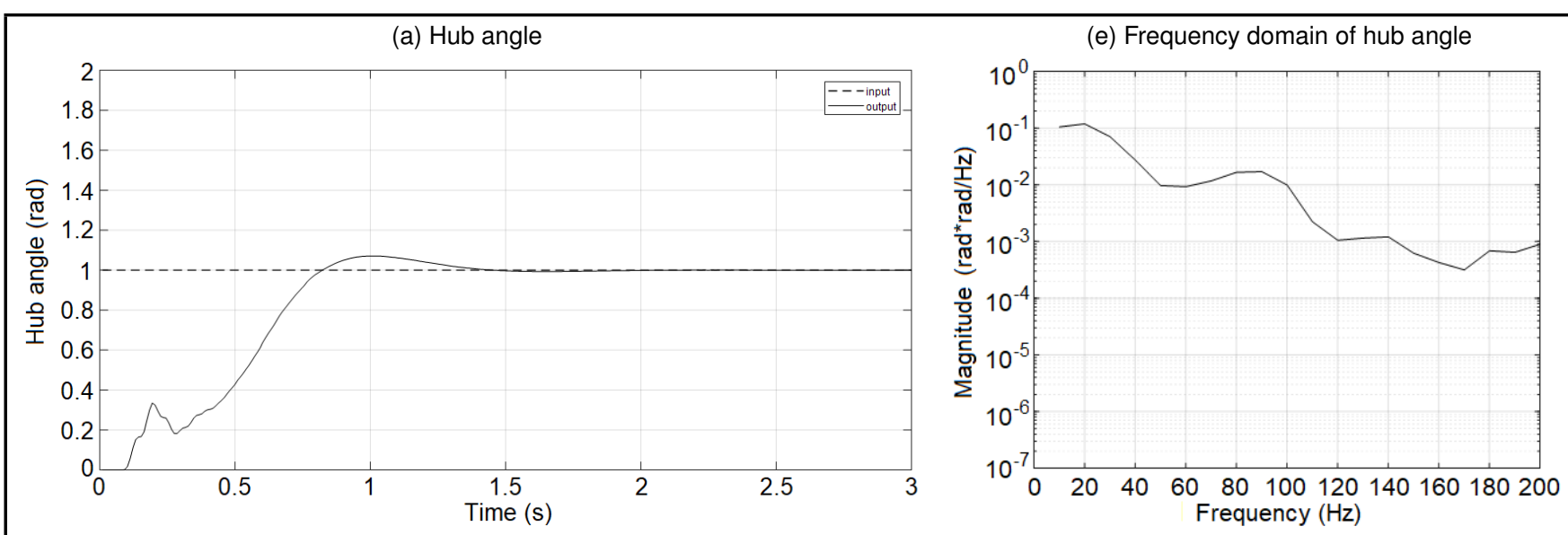

(b) Deflection

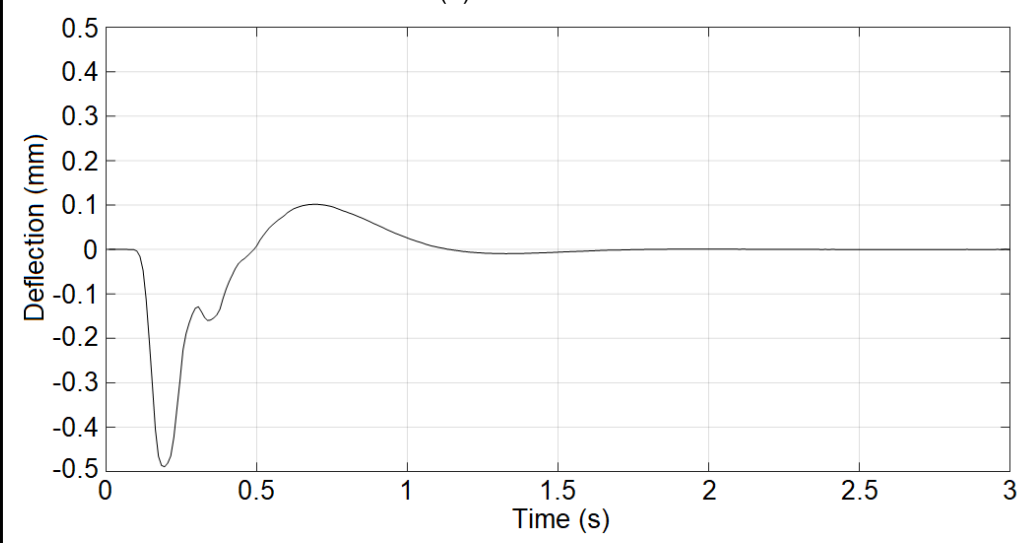

(f) Frequency domain of deflection

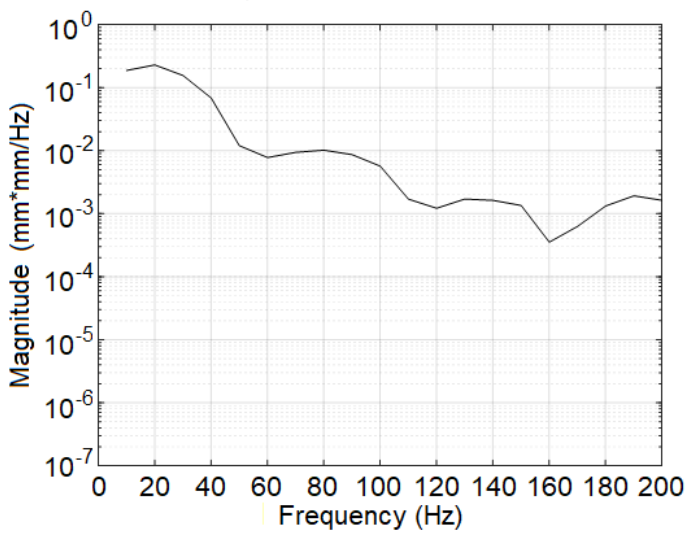

(c) Hub velocity

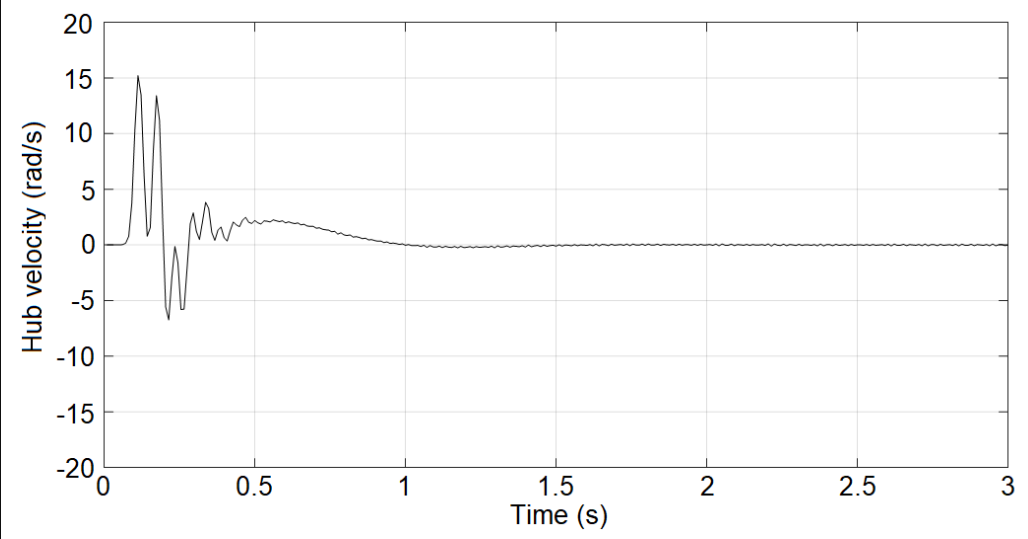

(g) Frequency domain of hub velocity

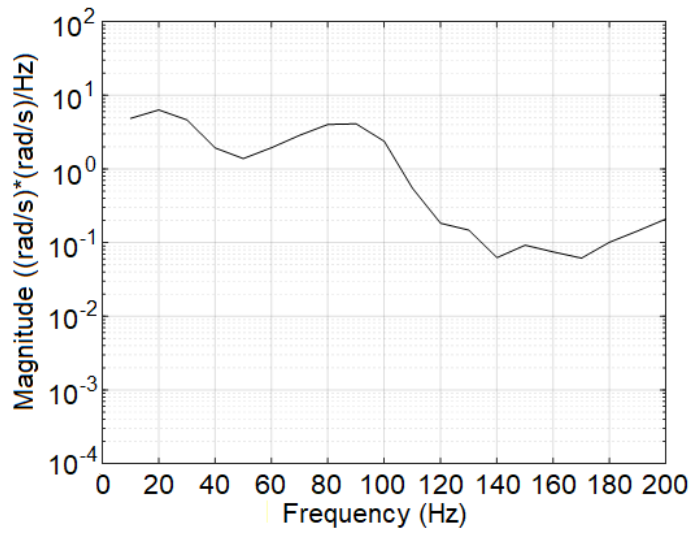

(d) End point residual

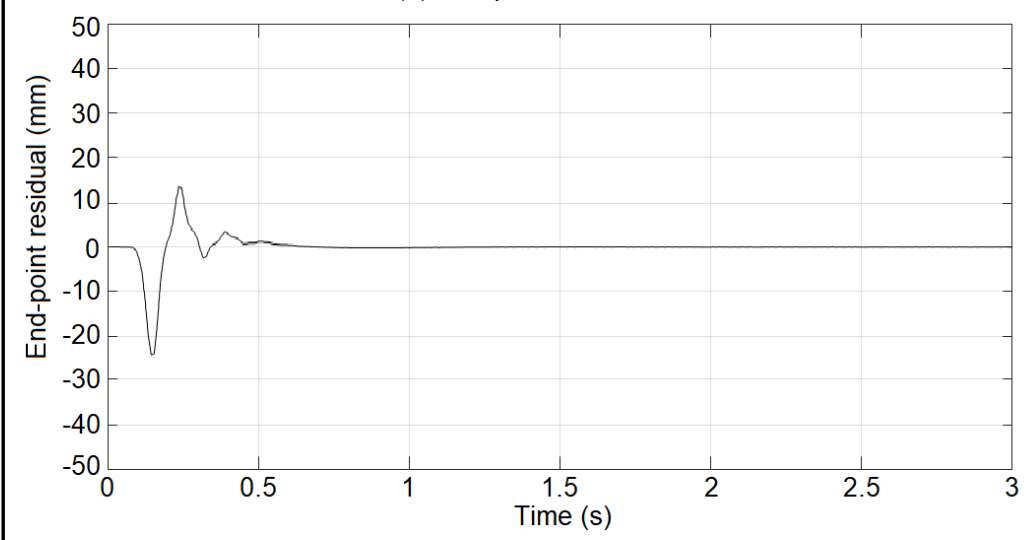

(h) Frequency domain of end point residual

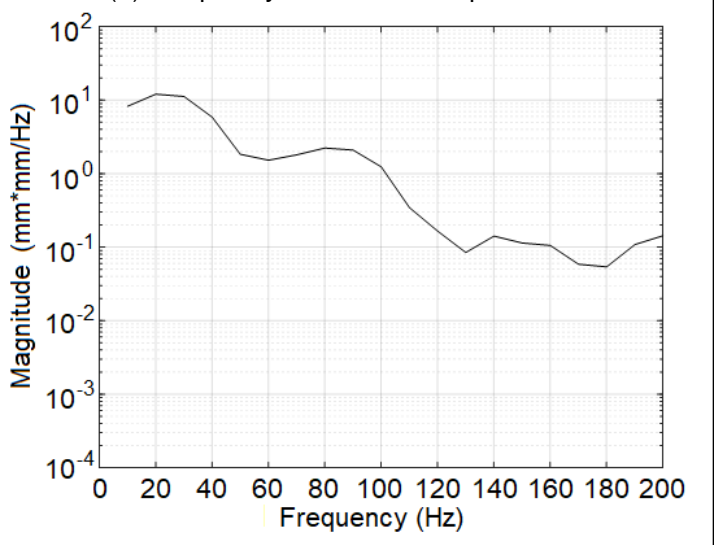

Figure 5. Simulated response of flexible one-link manipulator with payload of $0.1 \mathrm{~kg}$; Number of elements $=1$. 
Table 4. Relation between payload, number of elements and transient responses of flexible manipulator with SVF control and improved proportional gain.

\begin{tabular}{|c|c|c|c|c|}
\hline Load & \multicolumn{2}{|c|}{ Settling time (s) } & \multicolumn{2}{c|}{ Overshoot (\%) } \\
(kg) & $n=1$ & $n=2$ & $n=1$ & $n=2$ \\
\hline 0 & 0.85 & 0.67 & 6.62 & 6.50 \\
0.1 & 1.30 & 1.17 & 7.10 & 6.90 \\
0.2 & 1.58 & 1.49 & 7.20 & 7.00 \\
0.3 & 1.81 & 1.77 & 7.30 & 7.10 \\
\hline
\end{tabular}

Table 5. Relation between payload, number of elements, deflection, hub velocity and end-point residual responses of flexible manipulator with SVF control and improved proportional gain.

\begin{tabular}{|c|c|c|c|c|c|c||}
\hline \multirow{2}{*}{$\begin{array}{c}\text { Load } \\
(\mathrm{kg})\end{array}$} & \multicolumn{2}{|c|}{$\begin{array}{c}\text { Deflection } \\
(\mathrm{mm})\end{array}$} & \multicolumn{2}{c|}{$\begin{array}{c}\text { Hub velocity } \\
(\mathrm{rad} / \mathrm{s})\end{array}$} & \multicolumn{2}{|c|}{$\begin{array}{c}\text { End point residual } \\
(\mathrm{mm})\end{array}$} \\
& $n=1$ & $n=2$ & $n=1$ & $n=2$ & $n=1$ & $n=2$ \\
\hline 0 & 0.42 & 0.40 & 14.55 & 27.97 & 37.55 & 25.99 \\
0.1 & 0.49 & 0.46 & 15.22 & 23.57 & 24.40 & 23.27 \\
0.2 & 0.51 & 0.48 & 14.55 & 21.98 & 22.78 & 21.60 \\
0.3 & 0.52 & 0.49 & 13.80 & 20.94 & 22.04 & 20.65 \\
\hline
\end{tabular}

manipulator with a higher number of elements using a SFV control and proportional gain improves transient responses (settling time and overshoot) compared to that with a lower number of elements.

Figure 5 also shows the hub-angular, deflection, hub velocity, end-point deflection, and the spectral density of those aspects in the one-link flexible manipulator developed by the number of element 1 using a SVF control with an improved proportional gain with payload of $0.1 \mathrm{~kg}$. The maximum magnitudes of deflection, hub velocity and end-point residual responses of one-link flexible manipulator with a SVF control and improved proportional gain are presented in Table 5.

The deflection responses of flexible one-link manipulator incorporating payloads of $0.1 \mathrm{~kg}, 0.2 \mathrm{~kg}$, and $0.3 \mathrm{~kg}$ using a SVF control with improved proportional gain are also examined. Similar to the case without payload, the analysis on a SVF control with improved proportional gain shows that for both cases, it is noted that the greater number of elements of one-link flexible manipulators, the smaller the deflection magnitudes will be. Another thing to note is that the increasing number of payloads will impact the increase of maximum deflection. Similar to the case without payload, the one-link flexible manipulator with a higher number of elements with a SFV control and proportional gain has resulted in smaller deflections compared to that with lower number of elements.

Furthermore, it is found that the larger number of elements and the increase in payload will increase the value of the velocity hub. Similar to the case without payload, the one-link flexible manipulator with a higher number of elements using a SFV control with proportional gain has resulted in a faster hub velocity compared to that with lower number of elements.

Meanwhile, the increasing number of elements in a flexible one-link manipulator with a SVF control and improved proportional gain will decrease the end-point residual. Similar to the case without payload, the one-link flexible manipulator with a higher number of elements through a SFV control with proportional gain has resulted in a smaller end-point residual compared to that with lower number of elements.

Table 6 summarizes the relation between the number of elements and the resonance frequency of a flexible manipulator
Table 6. Relation between payload, number of element 1, and resonance frequency of flexible manipulator with SVF control and improved proportional gain.

\begin{tabular}{|c|c|c|c|c|}
\hline Freq. domain of & Load $(\mathrm{kg})$ & Mode 1 & Mode 2 & Mode 3 \\
\hline \multirow{3}{*}{ Hub angle } & 0 & 13.90 & 90.32 & 187.6 \\
& 0.1 & 20.01 & 90.05 & 180.01 \\
& 0.2 & 21.75 & 76.13 & 152.3 \\
& 0.3 & 22.74 & 74.59 & 147.8 \\
\hline \multirow{5}{*}{ Deflection } & 0 & 20.84 & 90.32 & 187.6 \\
& 0.1 & 20.01 & 80.04 & 190.1 \\
& 0.2 & 21.75 & 87 & 184.9 \\
Hub velocity & 0.3 & 22.74 & 68.22 & 147.8 \\
\hline & 0 & 20.84 & 90.32 & 187.6 \\
& 0.1 & 20.01 & 90.05 & 150.1 \\
End point residual & 0.3 & 21.75 & 87 & 184.9 \\
& 0 & 22.74 & 79.59 & 147.8 \\
\hline & 0.2 & 27.79 & 83.38 & 187.6 \\
& 0.3 & 22.74 & 68.22 & 125.1 \\
\hline
\end{tabular}

using a SVF control and an improved proportional gain $\bar{N}$ with varying payloads. The frequency responses of the hub angular, deflection, hub velocity and end-point residual are obtained. Similarly, in this work, the second mode of vibration is considered as the dominant mode for dynamic characterization of deflection. The level of hub angular, deflection, hub velocity and end-point residual with a SVF control and an improved proportional gain with a number of element 1 have been examined. Increasing the payload will result in a lower system resonance frequency for all system responses, including hub angular, deflection, hub velocity and end-point residual.

\section{CONCLUSIONS}

This study presents the performance comparison for the FE system model, as well as the development of a flexible one-link manipulator with SVF control-based LQR approach with improved proportional gain. Through practical technical steps, a SVF control with improved proportional gain approach is used to obtain input tracking of the one-link flexible manipulator under various payload conditions. The performance of a SVF control with an improved proportional gain has been assessed in its relation to input tracking capabilities, deflections, hub velocity, and end-point residual in both numbers of elements for the one-link flexible manipulator. The system performance is presented in the domains of time and frequency. Through SVF control and improved proportional gain, all desired performances for each loading condition can be achieved.

\section{REFERENCES}

1 Tokhi, M. O., Mohamed, Z., and Shaheed, M. H. Dynamic characterisation of a flexible manipulator system, Robotica, 19, 571-580, (2001). Retrieved from http://eprints.whiterose.ac.uk/83192/

2 Dwivedy, S. K. and Eberhard, P. Dynamic analysis of flexible manipulators, a literature review, Mechanism and Machine Theory, 41, 749-777, (2006). https://dx.doi.org/10.1016/j.mechmachtheory.2006.01.014

3 Mohamed, Z., Khairudin, M., Husain, A. R., and Subudhi, B. Linear matrix inequality-based robust proportional 
derivative control of a two-link flexible manipulator, Journal of Vibration and Control, 22 (5), 1244-1256, (2016). https://dx.doi.org/10.1177/1077546314536427

${ }^{4}$ Martins, J. M., Mohamed, Z., Tokhi, M. O., Sa da Costa, J., and Botto, M. A. Approaches for dynamic modeling of flexible manipulator systems, IEE ProceedingsControl Theory and Application, 150, 401-411, (2003). https://dx.doi.org/10.1049/ip-cta:20030496

5 Ingole, S. B. and Chatterjee, A. Joint stiffness identification: a three-parameter joint model of cantilever beam, International Journal of Acoustics and Vibration, 22 (1), 313, (2017). https://dx.doi.org/10.20855/ijav.2017.22.1445

${ }^{6}$ Mohamed, Z. and Tokhi, M. O. Command shaping techniques for vibration control of a flexible manipulator system, Mechatronics, 14, 69-90, (2004). https://dx.doi.org/10.1016/S0957-4158(03)00013-8

7 Aoustin, Y., Chevallereau, C., Glumineau, A., and Moog, C. H. Experimental results for the end-effector control of a single flexible robotic arm, IEEE Transactions on Control Systems Technology, 2, 371-381, (1994). https://dx.doi.org/10.1109/87.338658

${ }^{8}$ Huang, Y. and Rong, H.-W. Free vibration of axially inhomogeneous beams that are made of functionally graded materials, International Journal of Acoustics and Vibration, 22 (1), 68-73, (2017) . https://dx.doi.org/10.20855/ijav.2017.22.1452

${ }^{9}$ Khairudin, M. PID control for a manipulator robot using internet networking and Matlab-based, Journal of Physics: Conference Series, 1140, 012004, (2018). https://dx.doi.org/10.1088/1742-6596/1140/1/012004

10 Nazemizadeh, M. and Nohooji H. R. An analysis of the finite element method applied on dynamic motion and maximum payload planning of flexible manipulators, Transactions of FAMENA, XXXIX (4), (2015). Retrieved from https://hrcak.srce.hr/152130

11 Dogan, M. and Istefanopulos, Y. Optimal nonlinear controller design for flexible robot manipulators with adaptive internal model, IET Control Theory and Applications, 1 (3), 770-778, (2007). https://dx.doi.org/10.1049/ietcta:20050272

12 Schindele, D. and Aschemann, H. Adaptive LQRcontrol design and friction compensation for flexible high-speed rack feeders, Journal of Computation and Nonlinear Dynamics, 9 (1), 1-9, (2014). https://dx.doi.org/10.1115/1.4025351
${ }^{13}$ Khairudin, M., Mohamed, Z., and Husain, A. R. System identification and LMI based robust PID control of a two-link flexible manipulator, Telkomnika, 12 (3), 125-132, (2014). https://dx.doi.org/10.12928/TELKOMNIKA.v12i4.293

14 Alandoli, E. A., Rashid, M. Z. A., and Sulaiman, M. A comparison of PID and LQR controllers for position tracking and vibration suppression of flexible link manipulator, Journal of Theoretical and Applied Information Technology, 95 (13), 2949-2955, (2017). Retrieved from http://www.jatit.org/volumes/Vol95No13/7Vo195No13.pdf

15 Rana, D. S. and Deepika Modelling, stability analysis and control of flexible single link robotic manipulator, International Journal of Advanced Research in Electrical, Electronics and Instrumentation Engineering, 3 (2), 7390-7401, (2014). Retrieved from https:// www.ijareeie.com/upload/2014/february/24_Modelling.pdf

${ }^{16}$ Razmjooy, N., Ramezani, M., and Namadchian, A. A new LQR optimal control for a single-link flexible joint robot manipulator based on grey wolf optimizer, Majlesi Journal of Electrical Engineering, 10 (3), (2016). Retrieved from https://www.academia.edu/38347834/A_New_LQR_ Optimal_Control_for_a_Single_Link_Flexible_Joint_Robot_ Manipulator_Based_on_Grey_Wolf_Optimizer

17 Deng, H., Sun, J. D., Huang, S. D., and Cao, G. Z. Vibration suppression of the flexible manipulator using optimal input shaper and linear quadratic regulator, In: Proc. of 12th International Conference on Ubiquitous Robots and Ambient Intelligence, Goyang, Korea, (2015). https://dx.doi.org/10.1109/URAI.2015.7358948

18 Tahir, N. M., Hassan, S. M., Mohamed, Z., and Ibrahim, A. G. Output based input shaping for optimal control of single link flexible manipulator, International Journal On Smart Sensing And Intelligent Systems, 10 (2), (2017). Retrieved from http://s2is.org/Issues/v10/n2/papers/paper7.pdf

19 Khairudin, M., Mohamed, Z., Husain, A. R. Dynamic model and robust control of flexible link robot manipulator, Telkomnika, 9 (2), 279-286, (2011). https://dx.doi.org/10.12928/telkomnika.v9i2.698

20 Tahir, N. M., Bature, A. A., Bature, U. I., Sambo, A. U., and Adamu, Y. B. Vibration and tracking control of a single link flexible manipulator using LQR and command shaping, Journal of Multidisciplinary Engineering Science and Technology, 3 (3), (2016). Retrieved from http://www.jmest.org/wpcontent/uploads/JMESTN42351442.pdf 